\title{
Biotinidase deficiency: the enzymatic defect in late-onset multiple carboxylase deficiency
}

\author{
Barry Wolf ${ }^{a, *}$, Robert E. Grier ${ }^{a}$, Richard J. Allen ${ }^{b}$, Stephen I. Goodman ${ }^{c}$ \\ and Craig L. Kien ${ }^{\text {d }}$ \\ ${ }^{a}$ Department of Human Genetics and Department of Pediatrics, Children's Medical Center, Medical College \\ of Virginia, Richmond, VA 23298 (USA); ${ }^{b}$ Departments of Pediatrics and Neurology, Section of Pediatric \\ Neurology, University of Michigan Medical Center, Ann Arbor, MI 48109 (USA); ${ }^{\circ}$ Department of \\ Pediatrics, University of Colorado School of Medicine, Denver, CO 80262 (USA) and d Departments of \\ Pediatrics and Biochemistry, Medical College of Wisconsin and the Milwaukee Children's Hospital, \\ Milwaukee, WI 53233 (USA)
}

(Received January 20th; revision March 20th, 1983)

\section{Summary}

Late-onset multiple carboxylase deficiency is characterized clinically by skin rash, alopecia, seizures and ataxia and occasionally by candidiasis and developmental delay. Biochemically, these individuals exhibit findings consistent with a combined deficiency of the biotin-dependent carboxylases. We have found that the activity of the enzyme biotinidase is also deficient in the sera of five affected children ( 0 to $3 \%$ of mean control activity, $5.80 \pm 0.89 \mathrm{nmol} \cdot \mathrm{min}^{-1} \cdot \mathrm{ml}^{-1}$ serum), and believe that it represents the primary biochemical defect in this disease. Biotinidase catalyzes the removal of biotin from the e-amino group of lysine, through which biotin is covalently bound to the four known human carboxylases, thereby regenerating biotin for reutilization. The deficient activity in our patients was not due to an inhibitor, particularly biotin. It is also not a consequence of feedback control in affected individuals under treatment with pharmacologic doses of biotin. The biotinidase activities of the parents of those children who were available for study were intermediate between deficient and normal values $(46 \%$ to $65 \%$ of mean normal activity). Children lacking biotinidase activity are unable to recycle biotin, and are thus entirely dependent upon exogenous biotin to prevent deficiency. Our findings indicate that the primary biochemical defect in late-onset multiple carboxylase deficiency is in biotinidase activity which is inherited as an autosomal recessive trait.

* Correspondent: Barry Wolf, Department of Human Genetics, Medical College of Virginia, P.O. Box 33, MCV Station, Richmond, VA 23298, USA. 


\section{Introduction}

There are two types of multiple carboxylase deficiency (MCD), the neonatal form in which the usual presenting symptoms are vomiting, lethargy and hypotonia, and the late-onset or juvenile form which is characterized by skin rash, conjunctivitis, alopecia, ataxia and occasionally by candidiasis and developmental delay [1,2]. Biochemically, patients with both disorders may exhibit ketolactic acidosis and organic aciduria caused by deficient activities of the biotin-dependent enzymes, propionyl $\mathrm{CoA}$ carboxylase, pyruvate carboxylase and $\beta$-methylcrotonyl $\mathrm{CoA}$ carboxylase [2]. Leukocyte enzyme activities are usually deficient prior to the administration of pharmacologic doses of biotin but become normal or nearly normal after treatment. The two disorders can be distinguished, however, by demonstrating carboxylase deficiency in fibroblasts in the neonatal form when the fibroblasts are grown in medium containing low concentrations of biotin, and normal enzyme activities under similar conditions in fibroblasts from the late-onset form. In addition, patients with the late-onset form frequently have lower than normal serum concentrations of biotin, whereas the serum biotin concentrations are normal in the neonatal variant. The neonatal disorder has recently been shown to result from a deficiency in the activity of holocarboxylase synthetase, the enzyme that covalently links biotin to the various apocarboxylases forming active enzymes $[3,4]$. Since cells from patients with the late-onset form of the disease have normal holocarboxylase synthetase activity [5], it has been assumed that this condition results from a defect in either the renal or intestinal transport of biotin and studies from several laboratories have therefore focused on the intestinal absorption and renal excretion of the vitamin [6-8]. However, the hepatic biotin pool is very large in comparison to the small amount of biotin which is normally absorbed from the diet or intestinal flora each day $[9,10]$. We therefore sought to test the alternative hypothesis that late-onset MCD results from an abnormality in biotin metabolism or turnover rather than a primary defect in biotin transport. The enzyme biotinidase (EC 3.5.1.12) is of critical importance in biotin metabolism; it catalyzes the removal of biotin from biocytin, $\epsilon-N$-biotinyl-lysine, which is a product of carboxylase degradation [11,12]. Significant biotinidase activity is found normally in liver, kidney, intestines and serum [13]. When we measured the activities of biotinidase in the serum of patients with late-onset MCD, we found that the activity of the enzyme was almost undetectable.

\section{Materials and methods}

Biotinidase activity was determined colorimetrically by measuring $p$-aminobenzoate liberation from $N$-biotinyl-p-aminobenzoate. $N$-Biotinyl-p-aminobenzoate was prepared by a modification of the method of Bayer and Wilchek [14]. Biotin- $N$ hydroxysuccinimide ester ( $1 \mathrm{mmol}$; Sigma, St. Louis, MO, USA) suspended in $3 \mathrm{ml}$ of dimethylformamide was added to $1 \mathrm{mmol}$ of $p$-aminobenzoate (Baker Chem. Co., Phillipsburg, NJ, USA) dissolved in $4 \mathrm{ml}$ of $0.2 \mathrm{~mol} / 1 \mathrm{NaHCO}_{3}$ at $0^{\circ} \mathrm{C}$, adjusted to pH 8.0 and reacted for $3 \mathrm{~h}$. The solvent was evaporated under reduced pressure and 
the $N$-biotinyl-p-aminobenzoate precipitated by the addition of $5 \mathrm{ml}$ of $10 \%$ citric acid. The precipitate was filtered and washed twice with water. Crystals obtained after air drying yielded $88 \mathrm{mg}$ of product. Chemical analysis of the product revealed: melting point $=296^{\circ} \mathrm{C}, \mathrm{C}=52.9 \%, \mathrm{H}=6.1 \%, \mathrm{~N}=11.3 \%$ and $\mathrm{S}=5.9 \%$ (Atlantic Microlab, Inc., Atlanta, GA, USA); expected $\left(\mathrm{C}_{17} \mathrm{H}_{21} \mathrm{O}_{4} \mathrm{~N}_{3} \mathrm{~S}, M_{\mathrm{r}} 363\right)$ : melting point $295-297^{\circ} \mathrm{C}$ [15], $\mathrm{C}=56 \%, \mathrm{H}=5.8 \%, \mathrm{~N}=11.5 \%, \mathrm{~S}=8.8 \%$. Cellulose thin layer chromatography (Eastman chromagram sheets 6064, Rochester, NY, USA) of our product revealed only single spots after development with 4-dimethylaminocinnamaldehyde [16] using two different solvent systems $\left(R_{\mathrm{F}}=0.55\right.$ in isopropanol/ammonia/water: $80: 5: 15$, by vol., and $R_{\mathrm{F}}=0.70 \mathrm{in}$ methanol/isoamyl alcohol/benzene/water/ammonia: $35: 17.5: 35: 10: 2.5$, by vol.). No free $p$-aminobenzoate or any other amino-aromatic compound was detectable in our product using the reaction described below.

Fasting human serum was obtained from eight normal donors, five children with clinical and biochemical features consistent with late-onset MCD (four males and one female) of four families, and six of their parents available for study. Serum was also obtained from a patient with documented holocarboxylase synthetase deficiency $[5,17]$ and from a patient who developed biotin deficiency due to parenteral hyperalimentation which lacked biotin and who has been treated approximately 3 years with $10 \mathrm{mg}$ of biotin daily [18]. Urine to be examined for the presence of biocytin was also obtained from several of the affected late-onset MCD patients.

Biotinidase activity was determined with slight modifications of the method of Knappe et al [15]. After a preincubation of $15 \mathrm{~min}$ at $37^{\circ} \mathrm{C}$, the enzyme assay was initiated by the addition of $0.1 \mathrm{ml}$ serum to $1.9 \mathrm{ml}$ of a mixture containing $200 \mu \mathrm{mol}$ potassium phosphate buffer, $\mathrm{pH} 6.0,20 \mu \mathrm{mol}$ EDTA, $0.5 \mathrm{mg}$ serum albumin, and 0.3 $\mu \mathrm{mol} N$-biotinyl-p-aminobenzoate bringing the final volume to $2 \mathrm{ml}(0.3 \mathrm{ml}$ of diluted serum was used in experiments to determine activity as a function of the amount of enzyme). The mixture was incubated for $30 \mathrm{~min}$ at $37^{\circ} \mathrm{C}$ and the reaction was terminated by the addition of $0.2 \mathrm{ml}$ of $30 \%$ trichloroacetic acid. The mixture was then centrifuged at $2000 \times \mathrm{g}$ for $10 \mathrm{~min} .1 .5 \mathrm{ml}$ of the supernatant was added to $0.5 \mathrm{ml}$ water. At room temperature, and at $3-\mathrm{min}$ intervals, $0.2 \mathrm{ml}$ of $0.1 \%$ sodium nitrite (made fresh daily), $0.2 \mathrm{ml}$ of $0.5 \%$ ammonium sulfamate and $0.2 \mathrm{ml}$ of $0.1 \%$ $N$-1-naphthyl ethylenediamine hydrochloride are added in succession and allowed to incubate for $10 \mathrm{~min}$ before measuring absorbance at $546 \mathrm{~nm}$. Biotinidase activity is expressed as nmol of $p$-aminobenzoate liberated per min per $\mathrm{ml}$ serum. No differences in biotinidase activity were noted between serum frozen immediately and that stored at $-70^{\circ} \mathrm{C}$ for up to 1 month.

Amino acid analyses of serum and urine were performed on a Durram amino acid analyzer using a Dowex OC-4A column and a sodium citrate buffer system. Amino acids were detected using $o$-phthalaldehyde (Fluropa; Pickering Products Mountainview, CA) (100 to 1000 times more sensitive than ninhydrin) at the excitation and emission wavelengths, $360 \mathrm{~nm}$ and $465 \mathrm{~nm}$, respectively.

Biotin was purchased from Sigma (St. Louis, MO, USA). Biocytin was kindly supplied by Merck, Sharp and Dohme Research Laboratories (Rahway, NJ, USA), and was also purchased from Sigma (St. Louis, MO). Avidin-sepharose (ultrogel) was purchased from LKB (Bromma, Sweden). 


\section{Results}

Biotinidase activity was measured in serum and in fibroblast extracts using the colorimetric assay. Biotinidase activity was linear up to $0.3 \mathrm{ml}$ of serum (Fig. IA). Biotinidase activity in $0.1 \mathrm{ml}$ of human serum was also found to be linear for up to $40 \mathrm{~min}$ (Fig. 1B). Biotinidase activity in fasting human serum from 18 children and adults was determined to be $5.80 \mathrm{nmol} \cdot \mathrm{min}^{-1} \cdot \mathrm{ml}^{-1}$ serum (Table I). The apparent $K_{\mathrm{m}}$ of $N$-biotinyl-p-aminobenzoate for biotinidase is $10 \mu \mathrm{mol} / 1$, which is in agreement with previously published values [15]. Fibroblast extracts from normal individuals incubated for several hours showed very little detectable activity by the colorimetric assay.

Biotinidase activity in the sera of all five of the children with the clinical features of late-onset MCD was almost undetectable (Table I). No increase in activity was found after increasing the concentration of substrate to $60 \mathrm{mmol} / 1$. The biotinidase activities of the serum from the six parents who were available for study were all intermediate between that of the affected children and normal controls (mean $=3.08$ $\pm 0.48 \mathrm{nmol} \cdot \mathrm{min}^{-1} \cdot \mathrm{ml}^{-1}$ serum) with a mean percentage of mean control activity of 53\% (Table I). Biotinidase activity in one patient with holocarboxylase synthetase deficiency was normal (Table I).

All of the affected children were receiving pharmacologic doses of biotin at the time the sera was collected. Although biotin has been shown to be a competitive inhibitor of biotinidase for biocytin we did not expect the biotin in the serum to interfere with our biotinidase assay because the concentration of $N$-biotinyl- $p$ aminobenzoate is 1000 times the highest molar concentration of biotin reported in a patient treated with biotin, just below $1 \mu \mathrm{g} / \mathrm{ml}[19]$, and the $K_{\mathrm{i}}$ of biotin for
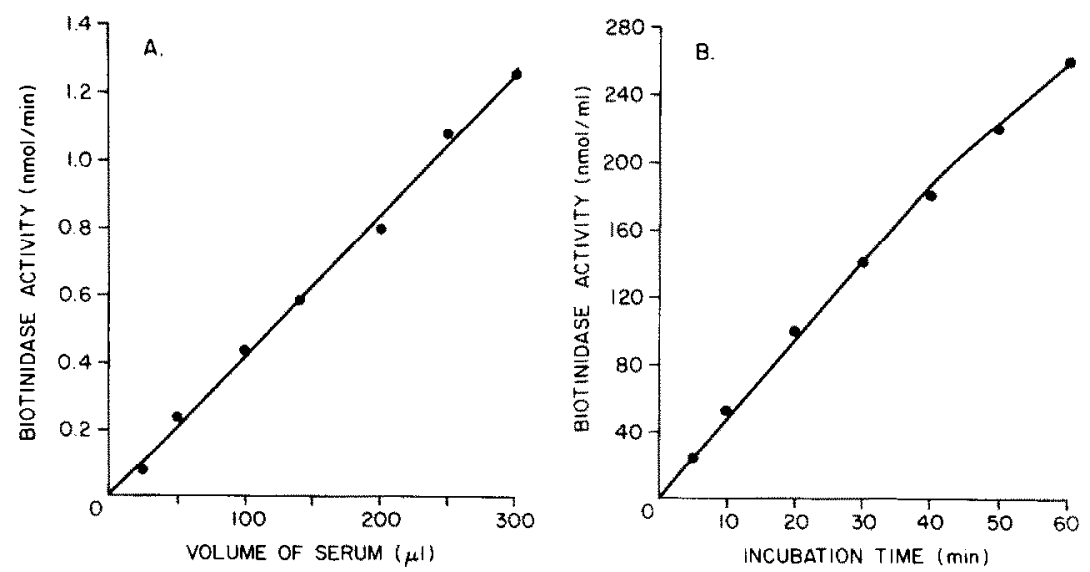

Fig. 1. Biotinidase activity measured in serum as a function of volume of serum and time of incubation. A. Biotinidase activity ( $p$-aminobenzoate liberated per $\min$ ) was measured colorimetrically using various incubation volumes of normal serum made up to $300 \mu \mathrm{l}$ with $50 \mathrm{mmol} / \mathrm{l}$ potassium phosphate buffer $\mathrm{pH}$ 6.0. The reaction was incubated for $30 \mathrm{~min}$ at $37^{\circ} \mathrm{C}$. B. Biotinidase activity ( $p$-aminobenzoate liberated per $\mathrm{ml}$ serum) was measured for various times of incubation ( $\mathrm{min}$ ) using $0.1 \mathrm{ml}$ of normal serum. 


\section{TABLE I}

Serum biotinidase activity in various individuals

\begin{tabular}{lll}
\hline Subject & $\begin{array}{l}\text { Biotinidase activity } \\
\left(\mathrm{nmol} \cdot \mathrm{min}^{-1} \cdot \mathrm{ml}^{-1} \text { serum) }\right.\end{array}$ & Mean control activity (\$) \\
\hline Proband 1 & $0.16^{*}$ & 3 \\
Proband 2 & 0.00 & 0 \\
Proband 3 & 0.00 & 0 \\
Proband 4 & 0.00 & 0 \\
Proband 5 & 0.18 & 3 \\
Mother (proband 1) & 2.64 & 46 \\
Mother (proband 2 and 3) & 3.36 & $5 f$ \\
Father (proband 2 and 3) & 3.80 & 65 \\
Mother (proband 4) & 2.70 & 47 \\
Father (proband 4) & 3.33 & 57 \\
Mother (proband 5) & 2.68 & 46 \\
Patient with holocarboxylase & 6.73 & 116 \\
$\quad$ synthetase deficiency & & 108 \\
Patient with biotin & & \\
$\quad$ deficiency receiving & 6.26 & 100 \\
10 mg of biotin/day & & \\
Normal controls ( $n=18)$ & & \\
$\quad$ mean \pm 1 SD & & \\
(range) & $5.80 \pm 0.89$ & \\
\hline
\end{tabular}

* All enzyme determinations were performed in duplicate and several values were the mean activities of two separate serum samples.

biotinidase is 10 to 50 times higher than the $K_{\mathrm{m}}$ of the substrate for biotinidase $[13,15]$. Nevertheless, we examined the effect of high concentrations of biotin on biotinidase activity. Biotin, $1 \mu \mathrm{g} / \mathrm{ml}$, was added to normal serum and incubated for $15 \mathrm{~min}$ at $37^{\circ} \mathrm{C}$. As expected, no decrease in activity was observed at this biotin concentration because of the great excess of artificial substrate to biotin used in the assay. In a separate study, sera from the affected children were pretreated with avidin-sepharose for $15 \mathrm{~min}$ at $37^{\circ} \mathrm{C}$ to remove free biotin. The matrix was sedimented by centrifugation at $1000 \times \mathrm{g}$ for $2 \mathrm{~min}$ and the serum removed and assayed for biotinidase activity. Under these conditions there was no increase in biotinidase activity in these samples. There was no change in biotinidase activity in normal serum treated similarly. Biotinidase activity was also normal in the serum of a patient who became biotin deficient while receiving parenteral hyperalimentation (Table 1). These findings demonstrate that the administration of pharmacologic doses of biotin does not result in decreased serum biotinidase activity.

Mixing experiments using proportional volumes of sera from affected children and controls resulted in the expected percentages of control activity, thus providing no evidence for the presence of an inhibitor of biotinidase in the affected sera. 
TABLE II

Effect of mixing various proportions of serum from an affected individual and a normal individual

\begin{tabular}{rcll}
\hline Normal serum (\%) & $\begin{array}{l}\text { Serum from affected } \\
\text { individual (\%) }\end{array}$ & $\begin{array}{l}\text { Observed biotinidase } \\
\text { activity } \\
\left(\mathrm{nmol} \cdot \mathrm{min}^{-1} \cdot \mathrm{ml}^{-1}\right)\end{array}$ & $\begin{array}{l}\text { Expected biotinidasc } \\
\text { activity } \\
\left(\mathrm{nmol} \cdot \mathrm{min}^{-1} \cdot \mathrm{ml}^{-1}\right)\end{array}$ \\
\hline 100 & 0 & 5.00 & 5.00 \\
75 & 25 & 4.02 & 3.75 \\
50 & 50 & 2.80 & 2.50 \\
25 & 75 & 1.40 & 1.25 \\
0 & 100 & 0.00 & 0.00 \\
\hline
\end{tabular}

Results of a representative mixing experiment are shown in Table II. In addition, mixing the sera of the various affected children $(1: 1, \mathrm{v} / \mathrm{v})$ did not result in complementation.

We examined the serum and urine of the affected patients and several normal individuals for the presence of biocytin by amino acid analysis. Since biocytin is an amino acid it reacts with fluorescent reagents specific for amino groups and can readily be detected by fluorometry. The retention time of biocytin was determined by running pure samples of biocytin and by running amino acid standards and normal serum with biocytin added. Biocytin eluted just after phenylalanine. The analysis of sera and urine from affected patients did not reveal any detectable biocytin at the limits of our sensitivity $(2.0 \mathrm{nmol} / \mathrm{ml})$.

\section{Discussion}

We have demonstrated almost undetectable biotinidase activity in the sera of five patients who had typical findings of late-onset MCD. Biotinidase activity was intermediate between deficient and normal values in the sera of all of the parents studied, with no overlap in the range of activities between the two groups. Mixing studies using sera from normal and affected individuals provided evidence that the observed deficiency did not result from an inhibitor in the serum of affected children. Similarly, high concentrations of biotin failed to inhibit the enzyme activity of normal subjects, essentially excluding a feedback control of serum biotinidase activity. These findings and the fact that both males and females are affected, are all consistent with the assumption that biotinidase deficiency is inherited as an autosomal recessive trait.

Our finding of biotinidase deficiency in patients with late-onset MCD suggests that the clinical and biochemical features of this disorder can best be understood as a defect in biotin metabolism. Biotinidase appears to be necessary for the normal recycling of biotin that has been incorporated into the various carboxylases and may represent an evolutionary adaptation by eukaryotic organisms to the loss of their ability to synthesize biotin. In normal individuals, the presence of biotinidase activity greatly reduces the extent of their dependency on exogenous biotin. In 
affected patients with late-onset MCD, the biotin salvage pathway is blocked and high concentrations of dietary biotin are therefore required to prevent symptoms of vitamin deficiency. Normally, in tissues with biotinidase activity, biotin is promptly liberated and made available for reutilization as soon as the carboxylases are degraded sufficiently to allow the enzyme to cleave biotin from the e-amino group of lysine. Patients with biotinidase deficiency are unable to cleave biotin from the partially degraded carboxylases resulting in continued digestion by proteases and peptidases to yield biocytin which cannot be further catabolized. Unfortunately, we were unable to detect biocytin in the plasma or urine of affected individuals. This is not surprising because of the limited sensitivity of the amino acid analyses even if all the measurable 'biotin' in serum or urine is actually biocytin.

In normal individuals, the intracellular regeneration of free biotin can occur in any tissue that contains biotinidase. Small quantities of biocytin may be transported out into the blood from tissues that lack the enzyme and are therefore dependent on biotin transport to meet their biosynthetic and metabolic needs. Further evidence for biotin recycling is provided by a study of the increase in carboxylase activities in peripheral blood leukocytes that occurs in normal individuals following the administration of pharmacologic doses of biotin [20]. The increase in enzyme activity begins almost immediately and reaches maximal levels in 7 to 10 days; however, the carboxylase activities return to pretreatment values after 5 to 6 weeks following discontinuation of the supplemental biotin intake. In patients with biotinidase deficiency, biocytin probably accumulates gradually as the available biotin pool is depleted, eventually creating a biotin-deficiency state in these children.

Studies in animals and man have shown that biotin deficiency can occur after the administration of avidin or eggs containing avidin thereby lowering the absorbable biotin available in the diet, or from the intestinal flora [10]. This deficiency state requires 6 to 8 weeks to achieve in rats and 8 to 10 weeks in man [10]. Presumably the symptoms of biotin deficiency would occur much more rapidly in a patient with late-onset MCD following the complete removal of exogenous biotin. Biotin deficiency can also be produced by completely restricting biotin in the diet as seen in patients treated by biotin-deficient parenteral alimentation $[18,21,22]$. In these conditions decreased dietary biotin is insufficient to replace the biotin, in the form of biocytin, which is slowly lost from the various tissues into the blood and is subsequently excreted in the urine. Children with biotinidase deficiency have biotin dependency, requiring continual replacement of their rapidly depleted tissue stores. The estimated hepatic biotin pool for a 1-year-old child is approximately $120 \mu \mathrm{g}$ biotin [9], whereas the pool size for an adult is about $675 \mu \mathrm{g}$. In contrast, the estimated total blood biotin contents are only $0.95 \mu \mathrm{g}$ and $2.4 \mu \mathrm{g}$, respectively. These 126-fold and 280-fold higher hepatic to plasma biotin pools indicate that biotin turnover is essential for normal biotin utilization. A continuous decrease in the hepatic biotin pool cannot likely be replaced by the small quantities of biotin absorbed from that in the normal diet. Supplementing these patients with pharmacologic doses of the vitamin rapidly increases their available biotin, and causes rapid clinical improvement.

There are very definite differences between the neonatal-onset form of MCD due 
to holocarboxylase synthetase deficiency and late-onset MCD. The latter is characterized by alopecia, ataxia, candidiasis, skin rash and conjunctivitis. Some of these features are common to those seen in the biotin-deficient state but others could result from a toxic effect of biocytin by, as yet, unknown mechanisms, possibly similar to those occurring in storage diseases.

The carboxylase deficiencies seen in this disease may be the result of the biotin-deficient state, or alternatively, biocytin may competitively inhibit holocarboxylase synthetase, as shown by the decreased incorporation of ${ }^{14} \mathrm{C}$-biotin into apocarboxylase in the presence of biocytin [23].

The serum biotin concentrations in individuals with late-onset MCD have been reported as normal or slightly below the normal range [2]. The biotin concentration in one of our patients was, in fact, slightly above the normal range. Since the methods for measuring biotin with avidin fail to discriminate between biotin and biocytin [9,24], it is not surprising that symptomatic children may have normal or nearly normal 'biotin' concentrations. Examining these same sera by microbiological bioassays using bacteria that grow in the presence of biotin, but not biocytin [12], may reveal that these patients are actually biotin deficient.

Several studies, examining the rise in serum concentration of biotin following the administration of varying quantities of oral biotin to patients with late-onset MCD, have suggested the presence of an abnormality in the intestinal absorption of biotin $[6,7]$. In vitro studies of intestinal biotin uptake in hamster have demonstrated that biocytin is a potent competitive inhibitor of biotin absorption [25]. Other reports have described abnormal urinary excretion of biotin in patients with late-onset MCD [8]. Since there is normally considerable biotinidase activity in the kidney, it seems plausible to suggest that in biotinidase deficiency abnormalities in renal transport may also result from competitive inhibition of normal biotin transport by the elevated concentrations of endogenous biocytin. In patients with biotinidase deficiency on a normal dietary biotin intake, the ratio of biocytin to biotin may gradually increase to a critical level at which biocytin can competitively inhibit these various transport pathways.

Although other causes of late-onset MCD are possible, our results indicate that one, if not the only cause, is biotinidase deficiency.

\section{Acknowledgements}

The authors thank Dr. Walter E. Nance for his invaluable discussions and suggestions and Terry Mayo for her excellent secretarial assistance. This is paper No. 173 of the Department of Human Genetics at the Medical College of Virginia.

This work was supported by grants from the National Institutes of Health (AM 25675) and from the National Foundation-March of Dimes (6-342). B.W. is the recipient of an NIH Research Career Development Award (AM 00677) and R.G. is the recipient of an NIH predoctoral training grant GM 07492. 


\section{References}

1 Sweetman L. Two forms of biotin-responsive multiple carboxylase deficiency. J Inher Metab Dis $1981 ; 4: 53-54$.

2 Wolf B, Feldman GL. The biotin-dependent carboxylase deficiencies. Am J Hum Genet 1982; 34: 699-716.

3 Burri BJ, Sweetman L, Nyhan WL. Mutant holocarboxylase synthetase: Evidence for the enzyme defect in early infantile biotin-responsive multiple carboxylase deficiency. J Clin Invest 1981; 68: 1491-1495.

4 Saunders ME, Sherwood WG, Duthie M. Surh L, Gravel RA. Evidence for a defect of holocarboxylase synthetase activity in cultured lymphoblasts from a patient with biotin-responsive multiple carboxylase deficiency. Am J Hum Genet 1982; 34: 590-601.

5 Sweetman L, Burri B. Abnormal holocarboxylase synthetases with elevated $K_{\mathrm{m}}$ values for biotin as the cause for one form of the inherited human disorder, biotin-responsive multiple carboxylase deficiency. Int Symp on Biotin-Dependent Enzymes, Glenelg, Australia 1982.

6 Munnich A, Saudubray JM, Carre G et al. Defective biotin absorption in multiple carboxylase deficiency. Lancet 1981; 2: 263.

7 Thoene JG, Lemons RM, Baker H. Impaired intestinal absorption of biotin in juvenile multiple carboxylase deficiency. N Engl J Med 1983; 308: 639-642.

8 Baumgartner R, Suormala T, Wick H, Geisert J. Renal loss of biotin: a cause of biotin-responsive multiple carboxylase deficiency. Pediatr Res 1982; 16: 41.

9 Baker H, Frank O, Matovich VB et al. A new assay method for biotin in blood, serum, urine, and tissues. Anal Biochem 1962; 3: 31-39.

10 Achuta Murthy PN, Mistry SP. Biotin. Prog Fed Nutr Sci 1977; 2: 405-455.

11 Thoma RW, Peterson WH. The enzymatic degradation of soluble bound biotin. J Biol Chem 1954; 210: $569-579$.

12 Wright LD, Driscoll CA, Boger WP. Biocytinase, an enzyme concerned with hydrolytic cleavage of biocytin. Proc Soc Exptl Biol Med 1954; 86: 335-337.

13 Pipsa J. Animal biotinidase. Ann Med Exp Biol Fenn 1965; 43, Suppl. 5: 5-39.

14 Bayer EA, Wilchek $M$. The use of the avidin-biotin complex as a tool in molecular biology. Methods Biochem Anal 1980; 26: 1-43.

15 Knappe J, Brommer W, Brederbick K. Reinigung und Eigenschaften der Biotinidase aus Schweinenieren und Lactobacillus casei. Biochem Z 1963; 338: 599-613.

16 McCormick DB, Roth JA. In: McCormick DB and Wright LD, eds. Methods in enzymology, Vol. 18(A). New York: Academic Press, 1970: 383-386.

17 Wolf B, Hsia YE, Sweetman L et al. Multiple carboxylase deficiency: clinical and biochemical improvement following biotin treatment. Pediatr 1981; 68: 113-118.

18 Kien CL, Kohler E, Goodman SI et al. Biotin-responsive in vivo carboxylase deficiency in two siblings with secretory diarrhea receiving total parenteral nutrition. J Pediatr 1981; 99: 546-550.

19 Packman S, Cowan MJ, Golbus MS et al. Prenatal treatment of biotin-responsive multiple carboxylase deficiency. Lancet 1982; 1: 1435-1439.

20 Wolf B, Rosenberg LE. Stimulation of propionyl CoA and $\beta$-methylcrotonyl $\mathrm{CoA}$ carboxylase activities in human leukocytes and cultured fibroblasts by biotin. Pediatr Res 1979; 13: 1275-1279.

21 Mock DM, Delorimer AA, Liehman WM, Sweetman L, Baker H. Biotin deficiency: an unusual complication of parenteral alimentation. N Engl J Med 1981; 304: 820-823.

$22 \mathrm{McClain} \mathrm{CJ}$, Baker H, Onstad GR. Biotin deficiency in an adult during home parenteral nutrition. J Am Med Assoc 1982; 247: 3116-3117.

23 Kosow DP, Huang SCh, Lane MD. Propionyl holocarboxylase synthesis. J Biol Chem 1962; 237: 3633-3639.

24 Landman AD. A sensitive assay for biotin analogs and biotin-proteins. Int J Vit Nutr Res 1976; 46: 310-313.

25 Spencer RP, Brody KR. Biotin transport by small intestine of rat, hamster, and other species. Am J Physiol 1964; 206: 653-657. 